\title{
Erratum to: Abusive Supervision and Subordinate Proactive Behavior: Joint Moderating Roles of Organizational Identification and Positive Affectivity
}

Qin $\mathrm{Xu}^{1} \cdot$ Guangxi Zhang ${ }^{2} \cdot$ Andrew Chan $^{3}$

Published online: 25 September 2017

(C) Springer Science+Business Media B.V. 2017

\section{Erratum to: J Bus Ethics}

DOI 10.1007/s10551-017-3691-3

The original version of this article was corrected: Figures 5 and 6 were updated.

The online version of the original article can be found under doi:10.1007/s10551-017-3691-3.

Qin Xu

qin1985@hotmail.com

1 School of Economics and Management, Southeast University, Nanjing 211189, People's Republic of China

2 College of Economics and Management, Zhejiang University of Technology, Hangzhou 310014, People's Republic of China

3 College of Business, City University of Hong Kong, Hong Kong, People's Republic of China 